DOI https://doi.org/10.36059/978-966-397-161-2/97-116

\title{
METHODS OF RESERCH OF EMOTIONAL INTELLIGENCE
}

\section{Mariia Stasiuk}

\section{INTRODUCTION}

A concept "emotional intelligence" is one of the most investigated for the last decades in the psychology. Due to the publications of D.Goulman an emotional intelligence was rooted in researches of sociological professions. Indisputably, there is importance of emotional intelligence in professional cooperation in the field of "man-man". There are some researches about the sphere of cooperation a "man-technique" and the role of emotionality. It is important to mention that on the first place is a contact of man with a computer technique in the field of information technologies. However, the organization of activity in IT-sphere involves combination of different relation processes and formats. Development intensity of information technologies is after both complication from a technical side (in particular, wide prospects of creation and perfection of artificial intelligence) and expansion of cooperating with people, including those who do not known a specific "technical" language. Accordingly, the emotional component of cooperation will become more and more urgent.

\section{Evolution of views on emotional intelligence}

Interest in exploring the socio-emotional sphere of the psyche, and not only general intelligence and thinking, has grown among scientists since the beginning of the twentieth century. The very idea of the emotional intelligence existence was formed from the concept of social intelligence that was actively developed by such scientists as E. Thorndike (1920), J. Guilford (1967), and G. Eysenck (1995). Independently of each other they floated the idea that people differ in their ability to understand other people, capacity to manage them, and productivity in interpersonal relationships. 
The discovery of emotional intelligence is related to a study carried out by R. Thorndike in the 1920s. He for the first time singled out such component of general intelligence as social intelligence, that is, the ability to understand others and act or behave wisely toward others. R. Thorndike believes that test-measured intelligence is abstract, and that there are also mechanical and social intelligences. Later on mechanical intelligence has been called practical intelligence. Social intelligence is described by the author as the ability to succeed in interpersonal situations and to manage men and women, boys and girls, that is, to act wisely in human relationships ${ }^{1}$.

G. Gardner came very close to the modern concept of emotional intelligence. He put forward the idea of multifactorial intelligence, which includes two variants of personal intelligence - interpersonal and intrapersonal. Emotional abilities, in turn, act as the emotional component in both these spheres ${ }^{2}$.

G. Gardner supported the idea of multiple intelligence proposed by L. Thurstone and, in 1983, suggested the existence of seven different forms of intelligence besides the traditional verbal and logical-mathematical ones. According to G. Gardner, these intellectual features of a person cover both interpersonal and interpersonal abilities. The scientist identified the following forms of intelligence: spatial, musical, linguistic, logical-mathematical, body-kinesthetic, interpersonal and intrapersonal.

Interpersonal intelligence is interpreted by the scientist as "an access to one's own emotional life, one's affects and emotions: the ability to recognize feelings immediately, name them, translate them into symbolic codes, and use them as a vehicle for understanding and controlling one's behavior".

According to G. Gardner, intrapersonal emotional intelligence is the ability to observe and differentiate other people's feelings and to use this knowledge to predict behavior.

1 Thorndike R. Stanford-Binet Intelligence Scale: 4th edition (Technical Manual) / Thorndike, R., Hagen, E., and Sater. - Chicago: Riverside. - 1986

${ }^{2}$ Gardner H. Multiple intelligences. N.Y., 1993. 
One of the first publications on the developed model of emotional intelligence belongs to Peter Salovey and John Mayer ${ }^{3}$. It is also the most well-known in both psychological and management literature, and is theoretically and empirically developed model of emotional intelligence as an aptitude. The first version of this model was proposed by scientists in 1990. They defined EI as the ability to detect one's own and others' feelings and emotions, to distinguish them and to use this information to direct one's actions".

The "early" model of emotional intelligence, proposed by P. Salovey and J. Mayer back in 1990, consisted of three types of abilities:

1) identification of emotions and their expression;

2) regulation of emotions;

3) the use of emotional information in the process of thinking.

The model was subsequently revised and supplemented with other cognitive functions and abilities. This revised version was based on the idea that emotions contain information about an individual's connection with other people and objects, that is, they actually "inform" the person about the nature of those relationships. Emotional intelligence in this model is seen as a hierarchical structure with consistent and interdependent levels. Analysis of the individual qualities involved in the processing of emotional information allowed the scientists to identify four components that are formed sequentially in the process of ontogeny:

1. Identification of emotions. It includes a number of related abilities - the perception of emotions (that is the ability to notice the mere existence of emotions), identification, adequate expression, distinguishing between true emotions and their imitation.

2. The use of emotions to increase the efficiency of thinking and activity. It includes the ability to use emotions to direct attention to important events, to evoke emotions that contribute to problem

3 Mayer J.D. Emotional intelligence: Popular or scientific psychology. [Electronic resource.] 2005. Mode of access: http://www.apa.org/monitor/sep99/ 
solving, to use mood swings as a tool for analyzing different views on a problem.

3. Understanding emotions. The ability to understand complexes of emotions, connections between emotions, changes from one emotion to another, reasons of emotions, verbal information about emotions.

4. Emotion management. The ability to control emotions, reduce the intensity of negative emotions, awareness of one's emotions, including unpleasant, the ability to solve emotionally charged problems without suppressing the associated negative emotions. It promotes personal growth and improvement of interpersonal relationships.

Emotional identification is a necessary basis for the further use of emotions in order to solve specific problems (Level 2). It is essential for understanding prior events that caused certain emotions or have resulted from them (Level 3). The ability to identify, understand and use emotions is necessary for emotional state self-regulation and for successful impact on the environment, that is, the regulation of own and others' emotions (Level 4). Thus, a high level of emotional intelligence provides that a person manages one's own emotions, perceives and governs them, does not suppress or displace "unwanted" emotions but regulates the expression of one or another emotion in each situation. Emotional intelligence begins with an awareness of one's own emotions, and only then is it possible to understand other people's emotions and the reasons that caused them.

Clinical physiologist Reuven Bar-On ${ }^{4}$ was one of the first who used the term EQ (emotional quotient) by analogy with IQ (intelligence quotient).

R. Bar-On understands emotional quotient as a set of noncognitive abilities, knowledge and skills that affect an individual's ability to meet environmental demands. R. Bar-On was the first one who tried to measure emotional intelligence. To do this, he tried to link the

${ }^{4}$ Bar-On R. The Bar “On Emotional Quotient Inventory (EQ” i): Technical Manual. Toronto: Multi "Health Systems, 1997 
degree of development of the emotional quotient with the overall quality of life. Actually, the questionnaire was first designed to test this concept. Gradually R. Bar-On developed a multifactorial approach to emotional intelligence in order to organize its quantification.

\section{Emotional intelligence as the sum of abilities according to Mayer and Salovey}

\begin{tabular}{|l|l|}
\hline \multicolumn{1}{|c|}{ Emotional intelligence } & \multicolumn{1}{c|}{ Emotional "stupidity" } \\
\hline $\begin{array}{l}\text { 1. the ability to perceive } \\
\text { emotions (to notice them) and to } \\
\text { express them adequately and } \\
\text { adaptively (emotional } \\
\text { perception and expression); }\end{array}$ & $\begin{array}{l}\text { lack of ability to notice emotions } \\
\text { (coldness), "indifference"; } \\
\text { inability to express emotions } \\
\text { adequately and adaptively; }\end{array}$ \\
\hline $\begin{array}{l}\text { 2. the ability to experience } \\
\text { (generate) feelings about } \\
\text { cognitive and other types of } \\
\text { activity (to enjoy the learning } \\
\text { new things - if there is a } \\
\text { motivation to learn; success in } \\
\text { the activity); }\end{array}$ & $\begin{array}{l}\text { activities. } \\
\text { ack orforming cognitive and other }\end{array}$ \\
\hline $\begin{array}{l}\text { 3. the ability to understand the } \\
\text { content of emotions, their } \\
\text { causes and effects (emotional } \\
\text { understanding) }\end{array}$ & $\begin{array}{l}\text { misunderstanding of the causes } \\
\text { and consequences of emotions, } \\
\text { inability to differentiate them }\end{array}$ \\
\hline $\begin{array}{l}\text { 4. the ability to regulate one's } \\
\text { own and others emotions (e.g. } \\
\text { to be able to calm others) } \\
\text { (emotional management) }\end{array}$ & $\begin{array}{l}\text { inability to regulate one's own } \\
\text { and others emotions }\end{array}$ \\
\hline
\end{tabular}

Due to results of this questionnaire, the author has created a five-factor model of emotional intelligence, which includes: intrapersonal qualities (ability to understand oneself and express one's feelings), interpersonal abilities (ability to accept, understand other 
people and interact with them), adaptability, stress management and general mood.

In the model of R. Bar-On, emotional intelligence is an intrapersonal trait, represented by emotional self-awareness, selfrespect, self-actualization, independence, self-confidence. Interpersonal traits are represented by empathy, interpersonal relationships and social responsibility. The third property - stress management - includes the ability to solve problems, a sense of reality, flexibility. Adaptability involves stress tolerance and impulsivity control. The general mood includes happiness and optimism of personality.

The intrapersonal sphere refers to a person's ability to understand and manage one's manifestations. It includes:

- introspection - the ability to recognize what a person is feeling and why, to understand how one's behavior affects other people

- assertiveness - the ability to express one's thoughts and feelings openly, and to defend one's own point of view.

- independence - the ability to direct and control yourself

- self-esteem - the ability to accept one's own strengths and weaknesses and feel good about yourself

- self-realization - the ability to realize one's full potential and be satisfied with one's own achievements.

The interpersonal sphere is about social skills and the ability to interact with others. To this area Bar-On includes:

- empathy - the ability to understand what other people may be feeling at the moment;

- social responsibility - the ability to collaborate with others and be a useful member of one's social group.

The adaptive sphere (adaptability) includes:

- realism - the ability to see reality as it is, filtering out one's own fears and projections;

- flexibility - the ability to relate one's own feelings, thoughts and actions to changing environmental conditions;

- problem-solving skills - the ability to identify a problem and establish an effective solution. 
Stress management - this sphere of emotional intelligence refers to the ability to withstand stress and control one's impulses. It includes:

- resistance to stress - person's ability to remain calm and constructive in adverse conditions;

- impulse control - the ability to delay the impulse of activity.

General mood includes:

- optimism - person's ability to maintain a realistic and positive attitude;

- life satisfaction - the ability to be satisfied with one's life and to make others feel joy.

The author considers an emotionally capable person as the one with high adaptive potential which includes stress tolerance and impulse control, stress management through the ability to solve problems, flexible approaches to finding the optimal solution based on the feeling of reality

In 1995, Daniel Goleman ${ }^{5}$ expanded and publicized the early model of emotional intelligence of J. Mayer and P. Salovey. To those components that were already highlighted (emotional identification, expression and regulation; use of emotional information) he added enthusiasm, persistence and social skills.

Published in 1995, D. Goleman's book "Emotional Intelligence" has not only become extremely popular in academia but also widespread among ordinary readers. It has actually initiated the development of the topic of emotional intelligence in management and business. D. Goleman subsequently finalized the structure of emotional intelligence, which then included four components - selfawareness, self-control, social sensitivity, relationship management and 18 related skills.

Emotional self-awareness implies the ability to understand one's emotions and their impact on one's psychological state and use of intuition when making decisions. Also, the concept of emotional self-

\footnotetext{
${ }^{5}$ Goleman D. Emotional intelligence. New York: Bantam Books, 1995.
} 
awareness involves accurate self-assessment, that is, acceptance of one's personal strengths and weaknesses and self-confidence.

Self-control includes the ability to restrain impulses, frankness (as honesty and directness) and adaptability, that is, flexibility in adapting to changes, the will to win, initiative, optimism and social skills.

According to D. Goleman, social sensitivity includes: compassion, i.e. the ability to understand the feelings of others, empathy, so-called "business awareness" (attention to current events), and positive attitudes toward others (courtesy).

Relationship management as a structural component of emotional intelligence implies inspiration, influence and contributing to changes, conflict management, teamwork and collaboration.

The dispositional model of emotional intelligence was proposed by English researchers K.V. Petrides and A. Furnham ${ }^{6}$. This model connects certain personality traits with the development level of person's emotional intelligence and emotional functioning as a whole. When describing emotional intelligence K.V. Petrides and A. Furnham use not only the set of abilities proposed by Mayer and Salovey, but also suggest that its dispositional components should be taken into account. The authors of this model of emotional intelligence talk about its dependence on the style of behavior, experience and context of the situation, and admit that the emotional experience of the individual is subjective.

Aspects of identifying dispositional EI for an adult

\begin{tabular}{|l|l|}
\hline \multicolumn{1}{|c|}{ Aspects of identifying } & \multicolumn{1}{|c|}{$\begin{array}{c}\text { High levels of EI identifying } \\
\text { indicate that a person }\end{array}$} \\
\hline \multicolumn{1}{|c|}{$\mathbf{1}$} & \multicolumn{1}{c|}{$\mathbf{2}$} \\
\hline Adaptability & $\begin{array}{l}\text { perceives itself as flexible, ready to } \\
\text { adapt to new living conditions }\end{array}$ \\
\hline Assertiveness & $\begin{array}{l}\text { is straightforward, frank, has the } \\
\text { will to protect others' rights }\end{array}$ \\
\hline
\end{tabular}

${ }^{6}$ Petrides K.V., Furnham A. On the dimensional structure of emotional intelligence // Personality and Individual Differences. 2000. V. 29. 
End of table

\begin{tabular}{|c|c|}
\hline 1 & 2 \\
\hline $\begin{array}{l}\text { Awareness of your own } \\
\text { emotions and other people's } \\
\text { emotions }\end{array}$ & $\begin{array}{l}\text { is able to clearly perceive one's } \\
\text { own and other people's emotions } \\
\text { and feelings }\end{array}$ \\
\hline on expression & $\begin{array}{l}\text { capable to adequately convey one's } \\
\text { feelings in communication with } \\
\text { other people }\end{array}$ \\
\hline $\begin{array}{l}\text { Regulating other people's } \\
\text { emotions }\end{array}$ & $\begin{array}{l}\text { can influence other people's } \\
\text { feelings }\end{array}$ \\
\hline Emotional self-regulation & $\begin{array}{l}\text { is able to control one's own } \\
\text { emotions }\end{array}$ \\
\hline (low) & not succumb to impulses \\
\hline $\begin{array}{l}\text { Relationships with other } \\
\text { people }\end{array}$ & $\begin{array}{l}\text { is able to maintain friendly and } \\
\text { healthy personal relationships with } \\
\text { others }\end{array}$ \\
\hline $\mathrm{S}$ & feels successful and cc \\
\hline Self & $\begin{array}{l}\text { is motivated to achievement and } \\
\text { demonstrates low probability of } \\
\text { losing confidence in the face of } \\
\text { adversity }\end{array}$ \\
\hline Soci & has high social skills \\
\hline Stress management & $\begin{array}{l}\text { is able to withstand pressure and } \\
\text { regulate stress }\end{array}$ \\
\hline Empathy as a trait & $\begin{array}{l}\text { is ready to sympathize with the } \\
\text { other person }\end{array}$ \\
\hline $\begin{array}{l}\text { Happiness as a personality } \\
\text { trait }\end{array}$ & $\begin{array}{l}\text { feels joy and satisfaction with } \\
\text { one's own life }\end{array}$ \\
\hline Optimisr & $\begin{array}{l}\text { is confident and ready to see first } \\
\text { and foremost "the bright side of } \\
\text { life". }\end{array}$ \\
\hline
\end{tabular}

The most famous concept of emotional intelligence in the countries of the former Soviet Union is the one proposed by 
D. Liusin ${ }^{7}$. Building on previous theories, he defines emotional intelligence as the ability to understand and manage one's and others' emotions. D. Liusin also considers incorrect the interpretation of emotional intelligence as a purely cognitive function.

D. Liusin writes that "emotional intelligence can be represented in the form of dual nature: cognitive abilities and personal characteristics". Considering the concept of emotional intelligence, D. Liusin notes that "psychological education is forming throughout person's life and is influenced by factors that determine its level and individual characteristics".

D. Liusin explains that he interprets the concept of the ability to understand and manage emotions as follows:

- a person is able to recognize emotion, that is, to establish the existence of certain experience inside oneself or another person;

- a person is able to identify an emotion, that is, to determine what emotion he or another person experiences and to find a verbal equivalent;

- an ability to understand the reasons that caused a particular emotion and its consequences;

A person's ability to manage emotions implies that a person is able to:

- control the intensity of emotions, especially to muffle strong emotions;

- control the external display of emotions;

- evoke one or another emotion if necessary.

D. Liusin believes that the ability to understand and manage emotions can be directed both to one's own emotions and to the experiences of other people. Thus, D. Liusin supports the view of most researchers that emotional intelligence includes both the intrapersonal and the interpersonal spheres. This orientation of emotional

${ }^{7}$ Liusin D.V. Ability to understand emotions: Psychometric and cognitive aspects // GA. Emelianov (Ed.), Social learning in the era rapid political and economic change. M .: Sense, 2000. 
intelligence is supposed to implement different cognitive processes and skills, however directly related.

The author suggests that the ability to understand and manage the emotional sphere is closely related to the general personality traits, and requires in the first instance an interest in the inner world (including one's own), tendency to analyze behavior and to attach great importance to emotions. D. Liusin proposes to envisage emotional intelligence as a construct with a two-component nature on the one hand, it is connected with the cognitive sphere, on the other, with the personal properties of man.

Emotional intelligence is forming throughout person's life and is influenced by various factors, which shape its specificity and individual peculiarities. D. Liusin identifies three groups of such factors: cognitive abilities, ideas about emotions, peculiarities of emotionality.

D. Liusin emphasizes that intellectual tests and questionnaires can be used to measure the construct of emotional intelligence. Questionnaires that focus on reflection, rather than correctness of answer, are more suitable for measuring of intrapersonal emotional intelligence. When measuring interpersonal emotional intelligence it is more appropriate to use tasks (cases), but this raises some particular difficulties in determining the correct answer.

Thus, the most well-known and grounded theories of emotional intelligence were considered: the non-cognitive theory of R. Bar-On, the theory of emotional and intellectual abilities of J. Mayer and P. Salovey, the theory of emotional competence of D. Goleman, the dispositional approach of K.V. Petrides and A. Furnham and the twocomponent theory of D. Liusin. The common understanding in all these theories is that they define emotional intelligence as a set of abilities to understand and manage both one's own emotions and those of others.

At the present stage, most researchers of emotional intelligence define it as a set of emotional-cognitive abilities for social and psychological adaptation of the individual. People with high levels of emotional intelligence have an expressed ability to understand their 
own and others' emotions, are able to manage their emotional sphere and, as a result, are more adaptable, more effective in communicating and interacting with others.

\section{Methodology of the emotional intelligence research}

The research of emotional intelligence in a IT-sphere at post soviet sphere is not very popular. Basic researches of emotional intelligence in Russia are conducted by D. Liusin in a collaboration with the American researchers R.Roberts, Dzh.Metiuz and develops the ideas of emotional intelligence and its practical significance in the different spheres of human activity. Authors observed different methodologies of the emotional intelligence diagnostics that are based on various approaches to determination of this concept, compared their structure and fillingness. They grouped all methodologies for diagnostics of emotional intelligence in two sub-groups: 1) methodologies-questionnaires that concern an emotional intelligence as difficult formation with cognitive nature and as personal description; 2) methodologies-tests that consider the emotional intelligence as cognitive description. In the further works D. Liusin develops own methodology of emotional intelligence diagnostics based on the theory of structure and development possibilities.

F. Bruks, H. Veinberh, N. Virt, E. Deikstra, S. Makkonnell, M. L. Smulson, B. Shneiderman, R. Hebriel, V. Volkonska, Yu. Babaieva, A. Voiskunskyi and others investigated the personal characteristics of programists and workers in the IT sphere ${ }^{8}$. It is now possible to meet the particular publications, dedicated to the range of problems of the professional or emotional exhaustion, research of stress resistance and coping strategies, leader qualities and

8 Kuzmyna K. E. Personal features of professional users of computer technologies. Psychological and pedagogical support in the educational institutions of the Russian Federation of the formation of a person as a person at the stage of intergenerational transition of youth: Sat. articles / Under the general editorship of S.P. Ivanova. M Publishing house of Moscow Psychological and Social 2008. From the Institute, 180-185. 
communicative skills for the IT-sphere workers. M. Nekrestianova and S. Miasnykova ${ }^{9}$ are ones of the few who researches the emotional intelligenge in the emotional technology sphere, in particular its influence on leader success in IT sphere I. Rohozhkina proved the developing effect of programming studies, that contradicts the generally accepted idea about sphere narrowing of interests and certain predominance of cognitive processes.

O. Shnaider research the programmer psychology in Ukraine ${ }^{10}$. He investigated the emotional exhaustion of programmers in the light of alexithymia and emotional intelligence. However, in his researches the indexes of emotional intelligence act as auxiliary.

Within of this article the methodology of emotional intelligence in the workers at IT industry research will be studied. In particular, there is the tooling that will extend possibilities for research and development of emotional intelligence.

For the first time the term an emotional intelligence was used by P. Salouei and Dzh. Maiier. They understand this term as one of types of capabilities, in particular social. Accordingly this cognitive construct as one of the intellect types, scientists suggest to measure with the help of objective tests. Now there are two methodologies of these authors: MEIS and MSCEIT, the second methodology is the extended option of the first one. These methodologies are based on the 4-factorial model. Within the framework of this model an emotional intelligence is determined as a set of capabilities that have a hierarchical structure. These capabilities are incorporated in 4 "branches": 1) perception of emotions, 2) increases of thinking efficiency with the help of emotions, 3) understanding of emotions, 4) emotion management. Within these tests the investigated have to

\footnotetext{
${ }^{9}$ Nekrestyanova MS, Myasnikova SV Emotional intelligence as a factor in the success of a leader in the field of information technology Scientific research of graduates of the psychology department of SPbGU Publishing house: St. Petersburg State University. - TI-El 2013. - C. 172-179

${ }^{10}$ Schneider O. V. Psychologistichny especialists of the emerald warhorse Scientific notes in the sphere of informational technologies for the National Ostrozka Academy. Seria "Psychologists and Teachers". Vypot. 26. 2014. P. 144-148
} 
perform a task. These tasks are estimated with objective assessement. There are 2 types of assessement: expert and average estimations that were determines as certain part of investigated during methodology standardization. These methodologies have high validity and reliability. Russion translation and adaptation was carried out during 2008-2010 by the command of Institute of psychology of Russian Academy of Sciences researchers under the direction of E. Serhiienka and I. Vitrovoi. Adaptation was conducted by double translation from English to Russian and vice versa. Translation was not accomplished word for word, but with the use of terminology, usual for Russian native speakers, however alike after sounding. Images were unchanged in the text. It can cause difficulties in perception and interpretation of emotions in the stages which are typical for American society. Authors assure that modern television and internet give a wide idea about life in American society and that it can serve as good basis for the use of test.

Questionnaire R.Bar-On EQ is based on the model ofemotional intellect, that was worked out by R.Bar-On. He suggests to examine an emotional intelligence as construct, that unites all discognitive capabilities of people, that give an opportunity to cope with life situations. In the structure of its construct 5 subcomponents are marked: 1) cognition itself: realization of the emotions, confidence, self-esteem, self actualization; 2) interpersonal skills: empathy, interpersonal relations, social responsibility; 3) capacities for adaptation: problem solution, connection with reality, flexibility; 4) management of stress situations: resistance to stress, control over impulsiveness; 5) prevailing mood:happiness, optimism. Any empiric data that would be basis for this methodology are absent. It bases only on the theoretical analysis of literature and author hypothesis.

One of the most popular methodologies at post-soviet time is the methodology of M. Kholl. The authord istinguishes 5 scales: 1) emotional awareness, 2) emotional management 3) self-motivation, 4) empathy, 5) emotion recognition of other people. However in the literature there is no information about empiric data and psychometrics of this methodology. 
D. Liusin, based on the analysis of theories of emotional intelligence and methods for his study, developed his own theory. In his understanding of emotional intelligence is the ability to understand their and others' emotions and their management. The author is invited to consider these abilities in two dimensions: in an interpersonal and intrapersonal interaction. Methodology Approbation has taken place but standardization continues, accordingly, the data of reliability and validity of the methodology, which are now considered to be preliminary.

Analyzing the above-described Techniques It is possible to recommend the technique of studying emotional intelligence among the IT-sphere workers in Ukraine, in particular, in Lviv, D. Liusin's method. Such a choice is due to the relative simplicity of the technique, the clarity of the instruction and the lack of the need for translation. These criteria are important because, in the given conditions of study, firstly there are no instructors, ie the researcher will remain alone with the computer and the task: secondly, the Russian-language text in the original is available for understanding and analysis as both Ukrainian and Russian-speakers and does not require double translation. In addition, the mass methodology confirms the psychometric performance at an adequate level.

For a broad analysis of emotional intelligence, it is also important to analyze the related characteristics and personality characteristics that can be the basis for its formation. Usually researchers include alexithymia and emotional burnout in their programs. These indicators are important for understanding the formation and development of emotional intelligence, but often inadequate. To analyze the emotional intelligence of lawyers in the IT sphere it is also appropriate to study the features of social adaptation and anxiety.

Such a methodological complex will take into account the peculiarities of professional activity of IT specialists, in particular, programmers. The specificity of this activity is that the interaction of programmers in the professional core business with the technique. 
Some researchers note that programmers who write code have a specific structure for perception and analysis of information.

In particular, they have a high level of abstract thinking. Often their abstractions are complex, multilayered and multidimensional. They are inclined to categorize and perceive reality with a metaphor. The emotional sphere can be developed in different ways, but one important feature that makes them the difference between experiencing emotions and their expression. It makes confusion in the analysis, because the study of the emotional sphere by studying the expression of emotions can lead to false conclusions about the affinity of the emotional sphere. While the study of experiences can show quite different results, another group of researchers ${ }^{11}$ thus describes the psychological portrait of an "ideal" programmer:

- persistence/passivity: persistent man possesses the necessary initiative to work;

- introversion/extraordinary: in collective co-operation and in cooperation with the user, a friendly alien style of relationships;

- internal/external controllability: individuals are expressing internal control by their own subjectivity;

- high/low excitability, moderate levels of excitability contribute to increased productivity;

- high/low motivation: individuals with a high level of motivation can perform very difficult tasks;

- high/low tolerance for uncertainty: developers should be able to work in conditions where a small number of facts or components are clearly identified;

- it is necessary to make decisions of limited input data for making another decision need to have a tendency to some risk;

- the ability to be precise: in the final stages of solving the task requires special attention to the details and readiness to check it to consider each detail;

${ }^{11}$ Schneiderman B. lleiholo prohrammirovashi: human factors in iislitelnyh and information systems. Trans. with English. M. Panto it connection. 1984. - 304 p. 
- modesty: a good program should be too self-confident about the quality of their programs;

- the ability to overcome stress: in cases of lagging behind planned terms, the ability to work well in a stressful situation is required.

In the above list one can notice that emotionality is not singled out separately. However, the points of "high/low excitability", "high low motivation", "the ability to overcome stress" suggest the emotional basis of these components, both in terms of" activation "motivational and the approaches to I. Illin.

Another parallel between the features of the emotional sphere and the professional activity of programmers is traced in the studies of emotional burnout.

O. Schneider, as a result of the study of emotional burnout in programmers, found that the ability to manage their behavior through emotional management is associated with emotional burnout. The author assumes that in a situation when in the process of human activity, person is not able to find an optimal and adequate way of expressing their emotions, "suffering" activities, emotions are not so much an energy resource, as they inhibit motivation.

\section{CONCLUSIONS}

The development and substantiation of the methodology for the study of emotional intelligence of IT staffers is a significant stage in the research work. At the moment, a whole range of techniques for the study of emotional and that are different both the theoretical basis and understanding of the basic and the concept of the structure of tools. Taking into account the various features of the techniques for the study of emotional intelligence in Ukraine, it is suggested to use the technique of D. Liusin. For a broad understanding of the processes of development of emotional intelligence, adding to the research parameters of personal anxiety, situational anxiety, adaptation. the removal of others. For the wide understanding of processes of development, emotional intellect, adding to research of parameters, personality anxiety, situation anxiety, adaptation, acceptance other, 
self-perception, emotional comfort, aspiring to prevailing it can be enough informing. Thus, the prospects for the implementation of the results of research in practical activities in the professional and in the personal sphere are opened.

\section{SUMMARY}

Work is devoted to methodology of selection and description, their combination for research emotional intelligence at workers of IT sphere. It was analysed the necessity of wide study of processes of emotional sphere in the context of researching emotional intellidence. In particular, alexithymie, anxiety, emotional exhaustion and their possible intercommunications with forming and development of emotional intellect.

\section{REFERENCES}

1. Andreeva I.N. (2004) The concept and structure of emotional intelligence. Socio-psychological problems of mentality: International scientific-practical conference. Smolensk SSPU 2004. vol. 4 pp. 22-26.

2. Bar-On R. (1997) The Bar "On Emotional Quotient Inventory (EQ" i): Technical Manual. Toronto: Multi "Health Systems.

3. Buck R. (1991) Motivation, emotion and cognition: A developmental-interactionist view // Strongman K.N. (ed.). International review of studies on emotion V.T. Chichester: Wiley.

4. Gardner H. (1993) Multiple intelligences. N.Y.

5. Goleman D. (1995) Emotional intelligence. New York: Bantam Books.

6. Kuzmyna K. E. (2008) Personal features of professional users of computer technologies. Psychological and pedagogical support in the educational institutions of the Russian Federation of the formation of a person as a person at the stage of intergenerational transition of youth: Sat. articles / Under the general editorship of S.P. Ivanova. M Publishing house of Moscow Psychological and Social, pp. 180-185. 
7. Liusin D.V. (2000) Ability to understand emotions: Psychometric and cognitive aspects. GA. Emelianov (Ed.), Social learning in the era rapid political and economic change.

8. Mayer J.D. (2005) Emotional intelligence: Popular or scientific psychology. [Electronic resource.] Retrieved from: http://www.apa.org/monitor/sep99/

9. Mayer J.D., Salovey P., Caruso D.R., Sitarenios G. (2001) Emotional intelligence as a standard intelligence. Emotion. V. 1.

10. Nekrestyanova M.S., Myasnikova S.V. (2013) Emotional intelligence as a factor in the success of a leader in the field of information technology Scientific research of graduates of the psychology department of SPbGU Publishing house: St. Petersburg State University. pp. 172-179.

11. Petrides K.V., Furnham A. (2000) On the dimensional structure of emotional intelligence // Personality and Individual Differences. v. 29.

12. Roberts RD, Momyos D., Zaydncr M., Lyusin D.V. (2004) Emotional intelligence: problems of theory, measurement and application in practice Psychology. Journal of the Higher School of Economics. vol. 1. no 4. pp. 3-26.

13. Salovey P., Mayer J.D. Some final thoughts on personality and intelligence // Sternberg J., Ruzlis P. (Eds). (1994) Personality and intelligence. Cambridge: Cambr. Univ. Press.

14. Stasyuk M. (2017) Specialties of the Dimensional Sphere IT-cialis. Science and Education a New Dimension. Pedagogy and Psychology vol. (59) pp. 82-86 Retrieved from: http://seanewdim.com/ uploads/3/4/5/1/34511564/ped_psy_v59_134.pdf

15. Schneider O. V. (2014) Psychologistichny especialists of the emerald warhorse Scientific notes in the sphere of informational technologies for the National Ostrozka Academy. Seria "Psychologists and Teachers". vol. 26. 2014. pp. 144-148.

16. Schneiderman B. (1984) lleiholo prohrammirovashi: human factors in iislitelnyh and information systems. Trans. with English. M. Panto it connection. pp. 304. 
17. Thorndike R. (1986) Stanford-Binet Intelligence Scale: $4^{\text {th }}$ edition (Technical Manual) / Thorndike, R., Hagen, E., and Sater.

\section{Information about the author:} Mariia Stasiuk, Postgraduate Student at the Department of Psychology, Ivan Franko National University of Lviv 1, Universytets'ka str., Lviv, 79000, Ukraine ORCID ID: https://orcid.org/0000-0003-3926-6618 